\title{
Housing conditions and adverse birth outcomes among Indigenous people in Canada
}

\author{
Gabriel D. Shapiro ${ }^{1}$ (D) - Amanda J. Sheppard ${ }^{2,3} \cdot$ Angela Mashford-Pringle $^{3} \cdot$ Tracey Bushnik $^{4} \cdot$ Michael S. Kramer $^{1,5}$. \\ Jay S. Kaufman ${ }^{1} \cdot$ Seungmi Yang ${ }^{1}$
}

Received: 31 May 2020 / Accepted: 6 April 2021 / Published online: 26 May 2021

(C) The Canadian Public Health Association 2021

\begin{abstract}
Objectives Poor housing conditions and household crowding have been identified as important health concerns for Indigenous populations in many countries but have not been explored in relation to adverse birth outcomes in these populations. We investigated housing conditions and adverse birth outcomes in a nationally representative sample of Indigenous people in Canada.

Methods Data were from a cohort of births between May 2004 and May 2006 created by linking birth and infant death registration data with the 2006 Canadian census. Log-binomial regression was used to examine associations between housing variables (persons per room and needed household repairs) and three adverse birth outcomes: preterm birth (PTB), small-forgestational-age (SGA) birth, and infant mortality. Separate regression models were run for First Nations, Métis and Inuit mothers, with adjustment for parity and parental socio-economic variables.

Results Need for major household repairs was associated with a slightly increased risk of PTB among First Nations and Métis mothers (adjusted RRs 1.12 and 1.13, respectively; 95\% CI 0.94-1.34 and 0.89-1.44, respectively) and a moderately increased risk of infant death in all three groups $(\mathrm{aRR}=1.69,95 \% \mathrm{CI} 1.00-2.85)$. Household crowding was also associated with a slightly elevated risk of PTB in all three groups $(\mathrm{aRR}=1.10,95 \%$ CI $0.95-1.29)$ and with an increased risk of infant mortality among First Nations (aRR $=1.57,95 \%$ CI $0.97-2.53$ ).

Conclusion This study highlights the need to improve understanding of links between housing conditions and perinatal health outcomes in Indigenous populations, including examining cause-specific infant mortality in relation to housing characteristics.
\end{abstract}

\section{Résumé}

Objectif Les mauvaises conditions de logement et le surpeuplement ont été identifiés dans plusieurs pays comme étant des enjeux importants de santé chez les populations autochtones. Cependant, aucune étude n'a exploré les conditions de logement en lien avec les issues défavorables de la grossesse dans ces populations. C'est ce que nous avons examiné dans une cohorte de naissances de mères autochtones au Canada, représentative à l'échelle nationale.

Méthodes Nous avons analysé une cohorte de naissances survenues entre mai 2004 et mai 2006. Cette cohorte a été créée en couplant les données d'enregistrement des naissances et des décès avec les données du Recensement du Canada de 2006. Nous avons utilisé une régression binomiale logarithmique pour estimer les associations entre les conditions de logement (nombre de personnes par chambre et besoins de réparation du logement) et les taux de trois issues défavorables de la grossesse (naissance prématurée, les nouveau-nés petits pour l'âge gestationnel et la mortalité infantile). Des modèles séparés ont été construits pour

Gabriel D. Shapiro

gabriel.shapiro@mcgill.ca

1 Department of Epidemiology, Biostatistics and Occupational Health, McGill University, Purvis Hall, 1020 Pine Ave West, Montreal, Quebec H3A 1A2, Canada

2 Indigenous Cancer Control Unit, Cancer Care Ontario, 505 University Avenue, Toronto, Ontario M5G 2L7, Canada
3 Dalla Lana School of Public Health, University of Toronto, Health Sciences Building, 155 College Street, 6th Floor, Toronto, Ontario M5T 3M7, Canada

4 Health Analysis Division, Statistics Canada, 150 Tunney's Pasture Driveway, Ottawa, Ontario K1A 0T6, Canada

5 Department of Pediatrics, McGill University, 1001 Décarie Boulevard, Montreal, Quebec H4A 3J1, Canada 
les femmes des Premières Nations, inuites et métisses, en ajustant les analyses pour la parité et les variables socioéconomiques parentales.

Résultats Les besoins de réparation du logement ont été associés avec un risque ajusté légèrement augmenté de naissance prématurée parmi les mères des Premières Nations et métisses (RRs ajustés : 1,12 et 1,13, respectivement; IC de 95 \% : 0,94, 1,34 et $0,89,1,44$, respectivement) et avec un risque modérément élevé de la mortalité infantile dans les trois groupes (RRa $=$ $1,69$, IC de $95 \%: 1,00,2,85)$. Le surpeuplement du logement a été associé avec un risque légèrement augmenté de la naissance prématurée dans les trois groupes ( $\mathrm{RRa}=1,10, \mathrm{IC}$ de $95 \%: 0,95,1,29)$ et avec un risque élevé de la mortalité infantile parmi les Premières Nations ( $\mathrm{RRa}=1,57$, IC de $95 \%: 0,97,2,53)$.

Conclusion Cette étude souligne le besoin d'améliorer notre connaissance des liens entre les conditions du logement et les issues de la santé périnatale au sein des populations autochtones, y compris l'étude de la mortalité infantile par cause en association avec les conditions de logement.

Keywords Indigenous health $\cdot$ Canada $\cdot$ Adverse birth outcomes $\cdot$ Housing $\cdot$ Household crowding

Mots-clés Santé autochtone $\cdot$ Canada $\cdot$ issues défavorables de la grossesse $\cdot$ logement $\cdot$ surpeuplement

\section{Introduction}

Indigenous people experience a range of poorer health outcomes in comparison with their non-Indigenous counterparts (Reading \& Wein, 2013). Indigenous people are substantially more likely to live in substandard housing conditions, such as homes with mould or mildew, those lacking reliable and safe power supplies or basic safety equipment such as working smoke detectors, and those with structural deficiencies or in need of major repairs (Bailie \& Wayte, 2006; First Nations Information Governance Centre, 2012; Riva et al., 2014a, b). Indigenous people are also more likely to live in crowded households, as defined based on the number of inhabitants per habitable room or per bedroom (Bailie \& Wayte, 2006). The challenge of substandard and crowded housing conditions in First Nations communities in Canada has recently received increased attention, as limited progress has been made in improving housing for this population (First Nations Information Governance Centre, 2012). Substandard housing has been implicated in the spread of infectious disease among Indigenous people in Canada (Clark et al., 2002; First Nations Information Governance Centre, 2012; Khan et al., 2016; Thompson et al., 2020) and elsewhere (Bulkow et al., 2002; Jacoby et al., 2011; Spurling et al., 2014). Research in this area has served to highlight the consequences of poor housing on Indigenous health and the necessity of significant investment to improve housing in Indigenous communities. Links between housing conditions and perinatal health, however, have not been investigated in Indigenous populations to date.

Perinatal health outcomes are of particular importance, as sequelae of non-fatal adverse outcomes often persist into childhood and adulthood. Exploring the relationship between housing conditions and adverse birth outcomes presents substantial methodological challenges, given the limited data on household conditions and the rarity of the most severe outcomes. The 2006 Canadian Birth-Census Cohort (CanBCC) presents an opportunity to address some of these challenges and permits examination of associations in the three Indigenous populations in Canada (First Nations, Inuit and Métis), which has not previously been feasible at the national level (Bushnik et al., 2016). In the present study, we assessed self-reported need for household repairs and household crowding in relation to adverse perinatal outcomes among Indigenous people in Canada. Outcomes examined include preterm birth (PTB), small-for-gestational-age (SGA) birth, and infant mortality.

\section{Methods}

We analyzed singleton births from the 2006 CanBCC, created by linking Canadian birth/infant death registration data for births between May 2004 and May 2006 with data from the 2006 Canadian long-form census. Deterministic linkage rules were applied for each person on the birth record (child, mother, father) based on child's date of birth (DOB), child's sex, mother's DOB, father's DOB, and postal code of mother's residence at the time of the child's birth, along with names in conjunction with one or more of these linkage variables (Bushnik et al., 2016). The 2006 long-form census was distributed to a random sample of one fifth of households throughout Canada, with $100 \%$ of households in the Yukon, the Northwest Territories (excluding Whitehorse and Yellowknife), Nunavut, and Indian reserves, Indian settlements, Indian government districts and "terres réservées" eligible for enumeration using the long-form census (Statistics Canada, 2010). The cohort achieved an overall linkage rate of $90 \%$, with a false-positive match rate of $<1 \%$ (Bushnik et al., 2016). 
Indigenous identity was ascertained using the census question: "Is this person an Aboriginal person, that is, North American Indian, Métis or Inuit (Eskimo)?" Need for household repairs was ascertained using the census question: "Is this dwelling in need of any repairs?" Response choices were as follows: "No, only regular maintenance is needed (painting, furnace cleaning, etc.)"; "Yes, minor repairs are needed (missing or loose floor tiles, bricks or shingles, defective steps, railings or sidings, etc.)"; and "Yes, major repairs are needed (defective plumbing or electrical wiring, structural repairs to walls, floors or ceilings, etc.)".

To measure household crowding, the number of household inhabitants during the pregnancy was first estimated by taking the household size reported on the census form and subtracting 1 for all pregnancies, except for infants who did not survive to the census date. The number of persons per room in the household was then estimated by dividing the estimated number of inhabitants in the household at the time of the pregnancy by the number of bedrooms reported in the household plus two (Ruiz-Castell et al., 2015). This definition assumes that the total number of rooms in the household includes a living room and a kitchen, in addition to bedrooms (Ruiz-Castell et al., 2015). Household overcrowding is generally defined as more than 1 person per room (Ruiz-Castell et al., 2015). However, varying cutoffs have been used to define overcrowding, and the threshold across which a dwelling is deemed to be overcrowded and problematic for health differs between studies and health outcomes investigated (Riva et al., 2014b). In light of these considerations and because of the prevalence of households with one or fewer persons per room in the CanBCC, persons per room was categorized as $<1$, exactly one, or $>1$. Furthermore, while we defined persons per room based on the number of bedrooms reported in the household plus two, as in previous research (Ruiz-Castell et al., 2015), some studies have used the total number of all rooms in the house (Carrière et al., 2017). Accordingly, we conducted a sensitivity analysis using this definition.

The distributions of needed household repairs and persons per room were described within the three Indigenous populations (First Nations, Inuit and Métis). Log-binomial regression analyses were conducted using SUDAAN to estimate risk ratios and 95\% confidence intervals for associations of needed household repairs and persons per room with the three perinatal outcomes (PTB, birth before 37 weeks' gestation; SGA, sex-specific birth weight below the 10th percentile for gestational age based on the Canadian reference (Kramer et al., 2001); and infant mortality). We used bootstrap weights to account for the census sampling design and the linkage rates of the CanBCC (Bushnik et al., 2016).

Analyses were adjusted for available clinical and sociodemographic variables known to be associated with adverse birth outcomes and also plausibly associated with housing conditions, including maternal age, parity, household income quintile, and maternal and paternal education levels (Shapiro et al., 2017; Vogel et al., 2018). Parental education and household income quintile were taken from the census, while maternal age and parity were taken from birth registration data. To disentangle the effects of housing characteristics from those of other socio-economic variables and other parental characteristics besides housing, we conducted a sensitivity analysis without adjustment for parental education or household income, as well as completely unadjusted analyses. In accordance with the confidentiality requirements of the Statistics Act, analyses based on cells with an unweighted $n$ of less than 5 were suppressed.

Even with $100 \%$ sampling of certain areas for the longform census, the Indigenous groups are small, and given that they share many experiences of marginalization and discrimination, treating them as completely independent from one another may not be statistically justifiable. Therefore, after running the initial regression models, we "shrank" the estimates and variances for these groups toward a common Indigenous mean using empirical Bayes prediction from a random effects model (Raudenbush \& Bryk, 1985). This essentially considers an optimally weighted average between treating them as distinct populations with no unmeasured attributes in common vs. pooling them into a single group (Efron \& Morris, 1973). The weighting is conceptually similar to the $I^{2}$ in meta-analysis, which is the proportion of total variation in estimates that is due to heterogeneity, and therefore reflects both the sample sizes and the variation observed within each group.

Sample characteristics, rates of adverse outcomes and associations of needed household repairs and persons per room with outcomes among non-Indigenous mothers were compared with those among Indigenous mothers. Because housing conditions and their effects on health are likely to differ for First Nations mothers living within vs. outside of First Nations communities (reserves), we conducted a sensitivity analysis for First Nations mothers, stratifying by community residence.

All analysis plans were developed in consultation with our partners at the Ontario Native Women's Association. Consultations were held to ensure that the conceptual framework, methodology, and research focus for analyses of Indigenous populations were rooted in an Indigenous perspective and aligned with the priorities of Indigenous communities. Furthermore, our authorship team includes two researchers with extensive experience in collaborative research with Indigenous communities and organizations, and one of our team members is a member of the Timiskaming First Nation with over 10 years' experience with the federal government in Indigenous initiatives. Creation and analyses of the CanBCC were approved by the Pediatric Research Ethics Board of the McGill University Health Centre Research Institute. 


\section{Results}

A total of 17,498 Indigenous births were included in the analyses (Table 1). Roughly two thirds of First Nations mothers in the sample lived in homes needing minor or major repairs. Rates of household repairs needed were slightly lower for Métis and Inuit mothers. Approximately $30 \%$ of First Nations and Inuit mothers lived in homes needing major repairs, compared with just under $14 \%$ of Métis mothers. Under $5 \%$ of Métis lived in homes with more than 1 person per room, compared with $20 \%$ of First Nations mothers and $32 \%$ of Inuit mothers (Table 2).

Among First Nations mothers, crude rates of all three adverse outcomes were higher in households needing repairs. This overall pattern was also observed among Métis mothers. Rates of adverse outcomes did not vary as much or as consistently by needed household repairs among Inuit mothers. Rates of PTB and SGA did not vary greatly or consistently by household crowding. Infant mortality rates were highest in households with more than one person per room among First Nations (Table 2). Sample characteristics and rates of adverse outcomes for non-Indigenous mothers are shown for reference in Tables $\mathrm{S} 1$ and $\mathrm{S} 2$.

Results of fully adjusted regression analyses are shown in Figs. 1 and 2 and in Table S3. Major household repairs needed (Fig. 1) were associated with a slightly increased risk of PTB among First Nations and Métis mothers (adjusted risk ratio $(\mathrm{aRR})$ for First Nations mothers $=1.12,95 \%$ CI 0.94-1.34; aRR for Métis mothers $=1.13,95 \%$ CI $0.89-1.44$ ) and with a moderately increased risk of infant death in all three Indigenous groups $\left(\mathrm{aRR}=1.69,95 \%\right.$ CI $1.00-2.85 ; I^{2}=0$, indicating no observed heterogeneity among the three groups; thus, the groups were combined). Household crowding (more than one person per room) was associated with a slightly elevated risk of PTB in all three Indigenous groups (aRR for 3 Indigenous groups $=1.10,95 \%$ CI $0.95-1.29 ; I^{2}=0$ ) and with an increased risk of infant mortality among First Nations (aRR $=1.57,95 \%$ CI $0.97-2.53$ ). Associations between household crowding and fatal outcomes could not be examined among Métis and Inuit mothers due to low sample sizes. Significant associations were not observed between housing conditions and SGA birth. Results from unadjusted and partially adjusted regression analyses were similar to those from fully adjusted analyses (Tables S6 and S7).

In order to assess the robustness of results against different definitions of crowding, we reanalyzed the data with household crowding defined based on the total number of rooms instead of the number of bedrooms plus two. Rates of household crowding were slightly lower in all study groups (Table S8). However, the overall patterns of the associations between household crowding and adverse birth outcomes were similar to those found in the principal analyses (Table S9).
Household repairs were much more frequently needed among First Nations mothers living in-community than among those not living in-community, with $48 \%$ of incommunity homes needing major repairs vs. $18 \%$ of homes not in-community (Table S10). Household crowding (defined as in the principal analyses, based on the number of bedrooms plus two) was also much more common in First Nations communities $(33 \%$ of in-community homes had $>1$ person per room vs. $8 \%$ of homes not in-community). However, additional adjustment for First Nations community residence did not substantially change associations between these exposures and birth outcomes (Table S11).

\section{Discussion}

To our knowledge, this is the first study to investigate perinatal outcomes in relation to housing conditions using data from a national representative sample of Indigenous people. All three Indigenous populations exhibited elevated rates of need for household repairs in comparison with the non-Indigenous population. The rate of household crowding was similar between Métis and non-Indigenous homes but was more than 5 times as high in First Nations homes and over 7 times as high in Inuit homes compared with non-Indigenous homes. Observed rates of major repairs needed in our data were similar to those reported for the 2006 census overall (Statistics Canada, 2014). Household crowding for the overall 2006 census was calculated using all rooms within a dwelling, after excluding bathrooms, halls, vestibules and rooms used solely for business purposes. Despite the slightly different definition used in our study, rates of household crowding were comparable $(20 \%, 5 \%$ and $32 \%$ in our study for First Nations, Métis and Inuit, respectively, vs. $15 \%, 3 \%$ and $31 \%$ in the 2006 census overall), and primary results remained unchanged in our sensitivity analysis using the census definition (Statistics Canada, 2014).

In the First Nations and Métis populations, rates of adverse perinatal outcomes tended to be higher in households needing repairs, but this relationship was less consistent in the Inuit population. Rates of PTB and SGA did not vary substantially in relation to household crowding, whereas infant mortality rates were higher among First Nations mothers living in more crowded households. It is plausible that household crowding poses more severe health risks related to infection in infants than in pregnant women and fetuses.

Adjusted analyses suggested associations between need for major (but not minor) household repairs and slightly higher rates of PTB in the First Nations and Métis populations. Need for household repairs was associated with substantially higher infant mortality rates in the three Indigenous populations. Household crowding was associated with higher infant mortality rates in the First Nations population, while these 
Table 1 Parental characteristics by Indigenous identity, singleton births in Canada, 2006 Canadian Birth-Census Cohort $(N=17,498)$

\begin{tabular}{|c|c|c|c|c|c|c|}
\hline & \multirow{2}{*}{\multicolumn{2}{|c|}{$\frac{\text { First Nations }}{(n=13,505)}$}} & \multirow{2}{*}{\multicolumn{2}{|c|}{$\frac{\text { Métis }}{(n=2264)}$}} & \multirow{2}{*}{\multicolumn{2}{|c|}{$\frac{\text { Inuit }}{(n=1729)}$}} \\
\hline & & & & & & \\
\hline & Unweighted $N$ & Weighted \% & Unweighted $N$ & Weighted \% & Unweighted $N$ & Weighted \% \\
\hline \multicolumn{7}{|l|}{ Maternal age } \\
\hline$<25$ years & 6995 & 52.9 & 950 & 44.4 & 955 & 55.8 \\
\hline $25-29$ years & 3320 & 24.2 & 665 & 29.4 & 425 & 23.1 \\
\hline $30-34$ years & 2085 & 15.0 & 440 & 18.0 & 220 & 14.0 \\
\hline$\geq 35$ years & 1105 & 7.9 & 205 & 8.3 & 130 & 7.1 \\
\hline \multicolumn{7}{|l|}{ Marital status } \\
\hline Unmarried* (and not in common-law union) & 7925 & 73.5 & 955 & 54.0 & 1360 & 82.0 \\
\hline Married (including common-law unions) & 2705 & 26.5 & 780 & 46.0 & 300 & 18.0 \\
\hline \multicolumn{7}{|l|}{ Maternal education } \\
\hline Less than high school graduation & 7885 & 52.9 & 740 & 28.6 & 1150 & 62.4 \\
\hline High school graduation & 2850 & 23.2 & 625 & 29.4 & 260 & 17.4 \\
\hline Postsecondary diploma or university degree & 2730 & 23.9 & 890 & 42.1 & 320 & 20.2 \\
\hline \multicolumn{7}{|l|}{ Paternal education } \\
\hline Missing & 5460 & 40.1 & 715 & 29.9 & 860 & 48.1 \\
\hline Less than high school graduation & 4380 & 27.9 & 450 & 17.7 & 445 & 25.2 \\
\hline High school graduation & 1380 & 12.8 & 395 & 18.5 & 130 & 7.8 \\
\hline Postsecondary diploma or university degree & 2280 & 19.2 & 700 & 34.0 & 295 & 18.9 \\
\hline \multicolumn{7}{|l|}{ Parity } \\
\hline 1 & 4150 & 35.8 & 920 & 46.1 & 360 & 33.0 \\
\hline $2-3$ & 3170 & 26.2 & 695 & 30.2 & 260 & 20.9 \\
\hline$\geq 4$ & 6005 & 38.0 & 635 & 23.7 & 605 & 46.1 \\
\hline \multicolumn{7}{|l|}{ Maternal country of birth } \\
\hline Canada & 13,335 & 99.0 & \multirow{2}{*}{\multicolumn{2}{|c|}{ Suppressed }} & \multirow{2}{*}{\multicolumn{2}{|c|}{ Suppressed }} \\
\hline Not Canada & 125 & 1.0 & & & & \\
\hline \multicolumn{7}{|l|}{ Household income quintile } \\
\hline 1 (lowest) & 4645 & 39.0 & 570 & 27.1 & 165 & 15.8 \\
\hline 2 & 3455 & 24.3 & 530 & 22.8 & 325 & 18.6 \\
\hline 3 & 2555 & 17.1 & 420 & 17.0 & 325 & 17.1 \\
\hline 4 & 1740 & 11.8 & 395 & 17.6 & 420 & 22.7 \\
\hline 5 (highest) & 1110 & 7.7 & 350 & 15.5 & 490 & 25.8 \\
\hline
\end{tabular}

Unweighted cell counts are randomly rounded up or down to the nearest 5, in accordance with Statistics Canada disclosure regulations *Unmarried includes single, widowed, divorced, separated and never married, if not in a common-law union

relationships could not be examined in Métis and Inuit populations, owing to low cell counts.

Household crowding and needed household repairs have been identified as concerns relevant to the health of Indigenous populations in Canada (Ruiz-Castell et al., 2015; Carrière et al., 2017; Statistics Canada, 2017) and in other countries (Basnayake et al., 2017). Household crowding has been linked with tuberculosis in First Nations (Clark et al., 2002) and Inuit populations (Khan et al., 2016) and has been identified as a predictor of upper respiratory tract carriage of bacteria (Jacoby et al., 2011), skin infection (Bailie et al., 2005) and middle ear disease (Spurling et al., 2014) among
Indigenous children in Australia, and of hospitalization for respiratory syncytial virus infection among Alaska Native children (Bulkow et al., 2002). Household crowding was also associated with higher allostatic load in a study of Inuit individuals in Nunavik (Riva et al., 2014b) and with elevated rates of anemia among Inuit children in Nunavut (Pacey et al., 2011). Most recently, poor housing conditions in First Nations communities have been recognized as a barrier to preventing the spread of COVID-19 (Thompson et al., 2020).

In addition to cultural, historic and demographic differences between Indigenous populations, the existence of disparities in housing conditions between and within Indigenous 
Table 2 Adverse birth outcomes by household repairs needed and persons per room, stratified by Indigenous identity, 2006 Canadian Birth-Census Cohort

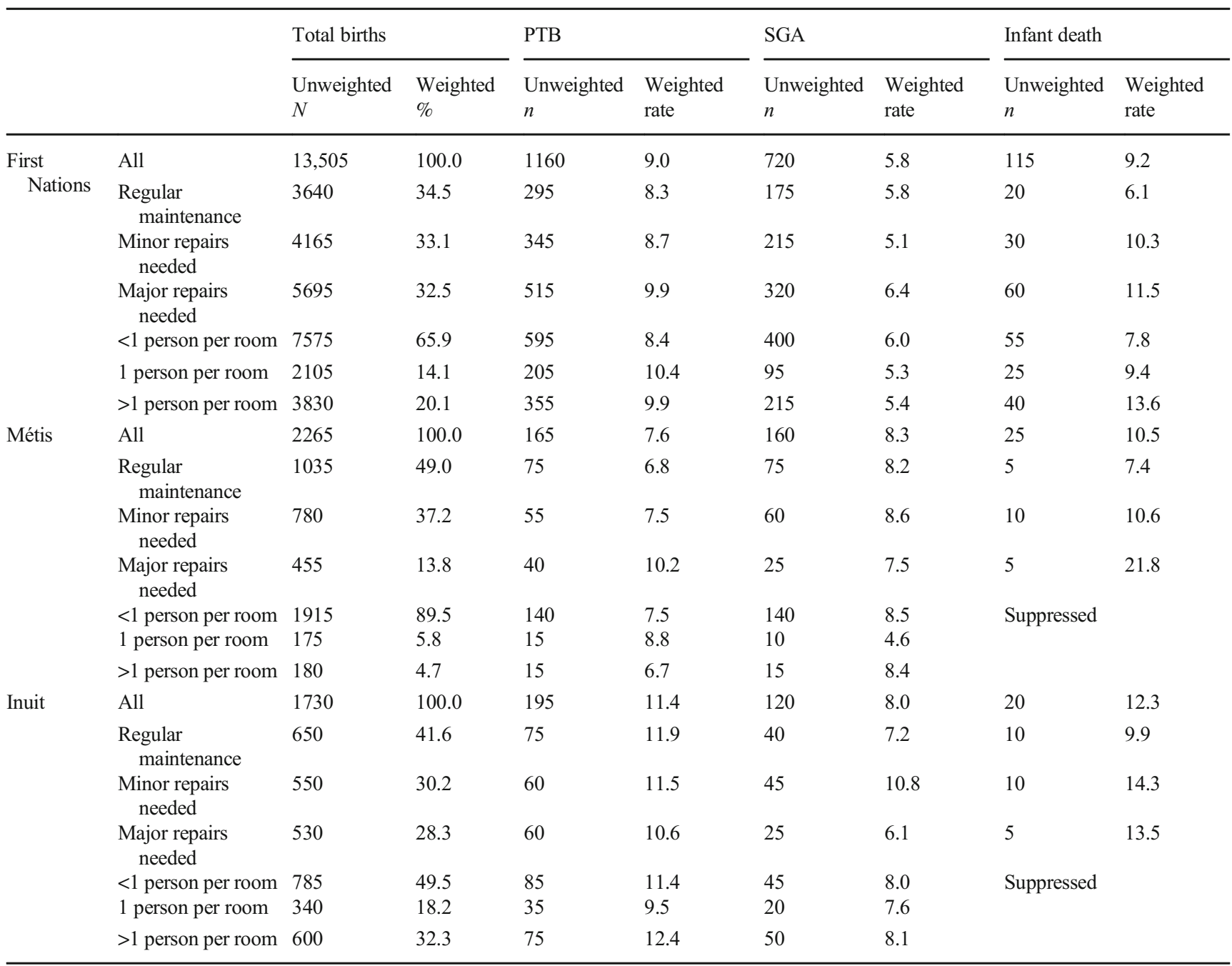

PTB, preterm birth; $S G A$, small for gestational age. Cell counts are randomly rounded up or down to the nearest 5, in accordance with Statistics Canada disclosure regulations. Rates for PTB and SGA are per 100; rates for infant death are per 1000

populations is an important reason to not treat Indigenous peoples as a homogenous group in health research, even research that is not specifically focused on housing. In Canada, First Nations mothers living outside of First Nations communities (reserves), Inuit who live outside of their traditional territory, and Métis people (with eight settlements located in northern Alberta as exceptions) live in the dominant society housing - that is, they are either a tenant of someone else's property or they own their own dwelling. Accordingly, adverse housing conditions may not pose as strong a health risk in these populations as for other Indigenous populations (de Leeuw et al., 2010). Conversely, Indigenous mothers who are homeless or do not have stable housing (i.e., living in transitional housing, shelters, or with friends or family) are likely to face different challenges impacting on perinatal health that go beyond the housing exposures captured in our study.
In a previous analysis of perinatal outcomes among First Nations mothers in the CanBCC, we found that mothers living in-community had slightly higher rates of large-for-gestationalage (LGA) birth and substantially higher rates of infant mortality overall compared with mothers not living in-community (Shapiro et al., 2018). Our analysis of housing exposures in the present study showed drastically higher rates of needed household repairs and household crowding for mothers living in First Nations communities compared with First Nations mothers not living in-community. However, we did not find evidence that these risk factors differentially affected birth outcomes by maternal residence. We did not have an indicator for Métis mothers residing on a Métis land base, which precluded further exploration of housing characteristics in this population.

Our findings reinforce existing calls to address inadequate housing conditions among Indigenous people and 


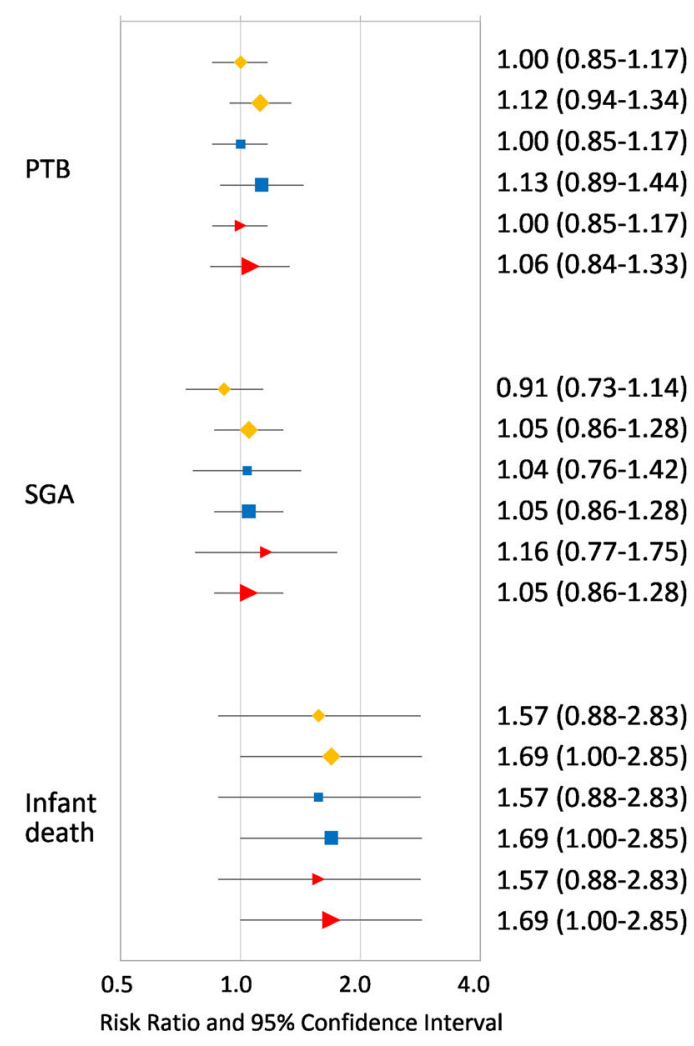

- First Nations, minor repairs needed

- Métis, minor repairs needed

- First Nations, major repairs needed

A Inuit, minor repairs needed
Métis, major repairs needed

A Inuit, major repairs needed

Fig. 1 Adjusted risk ratios of adverse birth outcomes by household repairs needed, stratified by Indigenous identity, 2006 Canadian BirthCensus Cohort. Reference category $=$ regular maintenance. Analyses adjusted for maternal age, parity, education, paternal education, and household income quintile. All estimates smoothed with empirical Bayes shrinkage

especially in First Nations communities. While housing disparities between Indigenous and non-Indigenous populations stem in part from historical and socio-economic factors, present-day racism is likely to play a role as well, especially for Indigenous people living in primarily nonIndigenous settings (Currie et al., 2012). Accordingly, improving housing conditions among Indigenous people in Canada will require addressing underlying systemic racism affecting these populations.

Our results provide preliminary evidence linking housing and perinatal health among Indigenous people in Canada. However, causal mechanisms underlying our findings are unclear. Our earlier analysis of infant mortality in the CanBCC revealed that rates of sudden infant death syndrome (SIDS) and deaths from infections, both of which plausibly relate to inadequate housing conditions, were several times higher in Indigenous people than in non-Indigenous Canadians (Sheppard et al., 2017). Unfortunately, we were unable to

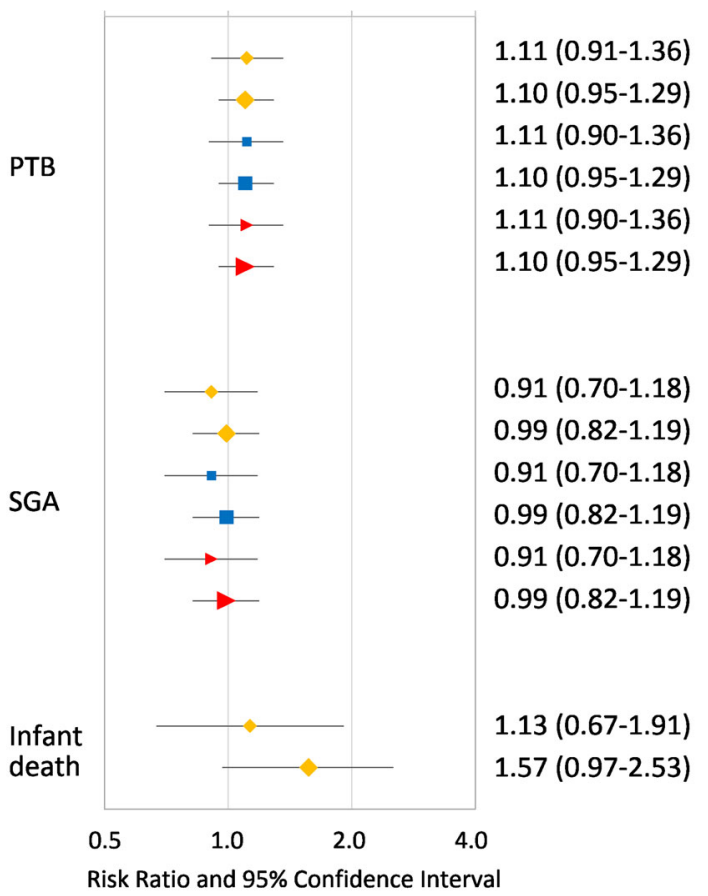

- First Nations, 1 person per room

First Nations, $>1$ person per room

- Métis, 1 person per room

Métis, $>1$ person per room

$\Delta$ Inuit, 1 person per room

$\Delta$ Inuit, $>1$ person per room

Fig. 2 Adjusted risk ratios of adverse birth outcomes by persons per room, stratified by Indigenous identity, 2006 Canadian Birth-Census Cohort. Reference category $=<1$ person per room. Analyses adjusted for maternal age, parity, education, paternal education, and household income quintile. All estimates smoothed with empirical Bayes shrinkage. Infant death could not be examined in the Métis or Inuit populations due to small cell sizes

examine cause of death in relation to housing characteristics in our sample, owing to small cell sizes. We recommend that future research examine how overcrowding may affect infant mortality in Indigenous communities through pathways including bed sharing, second-hand tobacco smoke, poor air quality due to use of wood stoves, or other potential risk factors.

Our principal analyses were adjusted for parental education and income, which in general were inversely associated with needed household repairs and household crowding in our study, although more crowded Inuit households tended to have higher incomes (data not shown in tables). Crude and adjusted estimates were similar to each other, however, suggesting that socio-economic variables in our data set did not explain the observed associations, and that our findings were indeed driven by the housing exposures examined. However, we did not have information on numerous other potentially relevant factors such as prenatal care and substance use; thus, our findings may still be subject to residual confounding. 
While First Nations communities and remote Inuit communities were oversampled for the long-form census, Indigenous people living in incompletely enumerated reserves or settlements were not included in the census. Moreover, the overall census response rate among Indigenous people living in or out of community is unknown. In addition, births to mothers younger than age 25 , which were disproportionately represented among Indigenous births, as well as births in the Northwest Territories and Nunavut, had lower linkage rates than for other groups in the CanBCC (Bushnik et al., 2016). Accordingly, the potential for biased estimates is elevated among Inuit mothers. Finally, long-form census data were not collected for residents of institutions (such as hospitals, nursing homes, jails) or shelters. Indigenous people are more likely than non-Indigenous people to live in shelters or correctional facilities (Sheppard et al., 2017). Therefore, data for the most vulnerable Indigenous women may not have been captured.

The exposure information for our study was self-reported and is subject to bias, particularly concerning need for household repairs. Examples of major and minor repairs were given in the census response choices, but there is inevitably some degree of subjectivity in what constitutes "needed" and "major" vs. "minor" repairs, and perceptions on needed household repairs could plausibly vary by ethnicity. Measuring household crowding based on the number of persons per room has also been questioned in reference to its cultural relevance to Indigenous households (Riva et al., 2014a, b).

\section{Conclusion}

Our study is the first to date to examine housing conditions in relation to perinatal outcomes in a national representative sample of Indigenous people in Canada. We found elevated rates of needed household repairs in First Nations, Métis and Inuit households in comparison with non-Indigenous households and elevated rates of household crowding in First Nations and Inuit households. Need for household repairs was associated with slightly higher rates of preterm birth and with substantially higher infant mortality rates. Household crowding was associated with elevated infant mortality rates among First Nations. Future studies should examine the impacts of housing in Indigenous communities and housing situations in urban and out-of-community areas. Understanding causal mechanisms underlying associations between housing conditions and perinatal health outcomes in Indigenous populations is one important priority. In addition, studies should be designed and powered to examine cause-specific infant mortality in relation to housing conditions.

\section{Contributions to knowledge}

What does this study add to existing knowledge?

- In a national representative sample of Indigenous people in Canada, analyses adjusted for multiple socio-economic characteristics suggest that housing conditions may exert an independent adverse impact on perinatal outcomes.

- While small numbers limited precision, housing variables were associated with a $57 \%$ to $69 \%$ higher adjusted risk of infant mortality in Indigenous populations.

What are the key implications for public health interventions, practice or policy?

- Our findings highlight the urgent need to improve housing conditions of Indigenous people in Canada, especially in First Nations communities. Such improvement may require addressing underlying systemic racism affecting these populations.

- Improved understanding of the mechanisms linking housing conditions and perinatal health can guide public health and housing policies for Indigenous communities.

Supplementary Information The online version contains supplementary material available at https://doi.org/10.17269/s41997-021-00527-2.

\section{References}

Bailie, R. S., \& Wayte, K. J. (2006). Housing and health in Indigenous communities: Key issues for housing and health improvement in remote Aboriginal and Torres Strait Islander communities. The Australian Journal of Rural Health, 14(5), 178-183.

Bailie, R. S., Stevens, M. R., McDonald, E., Halpin, S., Brewster, D., Robinson, G., \& Guthridge, S. (2005). Skin infection, housing and social circumstances in children living in remote Indigenous communities: Testing conceptual and methodological approaches. $B M C$ Public Health, 5, 128.

Basnayake, T. L., Morgan, L. C., \& Chang, A. B. (2017). The global burden of respiratory infections in indigenous children and adults: A review. Respirology, 22(8), 1518-1528.

Bulkow, L. R., Singleton, R. J., Karron, R. A., Harrison, L. H., \& Alaska RSV Study Group. (2002). Risk factors for severe respiratory syncytial virus infection among Alaska native children. Pediatrics, 109(2), 210-216.

Bushnik, T., Yang, S., Kramer, M., Kaufman, J., Sheppard, A., \& Wilkins, R. (2016). The 2006 Canadian Birth-Census Cohort. Health Reports, 27(1), 11-19.

Carrière, G. M., Garner, R., \& Sanmartin, C. (2017). Housing conditions and respiratory hospitalizations among First Nations people in Canada. Health Reports, 28(4), 9-15.

Clark, M., Riben, P., \& Nowgesic, E. (2002). The association of housing density, isolation and tuberculosis in Canadian First Nations communities. International Journal of Epidemiology, 31(5), 940-945. 
Currie, C. L., Wild, T. C., Schopflocher, D. P., Laing, L., \& Veugelers, P. (2012). Racial discrimination experienced by aboriginal university students in Canada. Canadian Journal of Psychiatry, 57(10), 617625 .

de Leeuw, S., Greenwood, M., \& Cameron, E. (2010). Deviant constructions: How governments preserve colonial narratives of addictions and poor mental health to intervene into the lives of Indigenous children and families in Canada. International Journal of Mental Health and Addiction, 8, 282-295.

Efron, B., \& Morris, C. (1973). Stein's estimation rule and its competitors-An empirical Bayes approach. Journal of the American Statistical Association, 68(341), 117-130.

First Nations Information Governance Centre. (2012). "First Nations Regional Health Survey (RHS) Phase 2 (2008/10) National Report on Adults, Youth and Children Living in First Nations Communities."

Jacoby, P., Carville, K. S., Hall, G., Riley, T. V., Bowman, J., Leach, A. J., Lehmann, D., \& T. Kalgoorlie Otitis Media Research Project. (2011). Crowding and other strong predictors of upper respiratory tract carriage of otitis media-related bacteria in Australian Aboriginal and non-Aboriginal children. The Pediatric Infectious Disease Journal, 30(6), 480-485.

Khan, F. A., Fox, G. J., Lee, R. S., Riva, M., Benedetti, A., Proulx, J. F., Jung, S., Hornby, K., Behr, M. A., \& Menzies, D. (2016). Housing and tuberculosis in an Inuit village in northern Quebec: a casecontrol study. CMAJ Open, 4(3), E496-E506.

Kramer, M. S., Platt, R. W., Wen, S. W., Joseph, K. S., Allen, A., Abrahamowicz, M., Blondel, B., Breart, G., \& S. Fetal/Infant Health Study Group of the Canadian Perinatal Surveillance. (2001). A new and improved population-based Canadian reference for birth weight for gestational age. Pediatrics, 108(2), E35.

Pacey, A., Weiler, H., \& Egeland, G. M. (2011). Low prevalence of irondeficiency anaemia among Inuit preschool children: Nunavut Inuit Child Health Survey, 2007-2008. Public Health Nutrition, 14(8), $1415-1423$

Raudenbush, S. W., \& Bryk, A. S. (1985). Empirical Bayes meta-analysis. Journal of Educational Statistics, 10(2), 75-98.

Reading, C. L. and F. Wein. (2013). "Health inequalities and the social determinants of Aboriginal peoples' health."

Riva, M., Larsen, C. V., \& Bjerregaard, P. (2014a). Household crowding and psychosocial health among Inuit in Greenland. International Journal of Public Health, 59(5), 739-748.

Riva, M., Plusquellec, P., Juster, R. P., Laouan-Sidi, E. A., Abdous, B., Lucas, M., Dery, S., \& Dewailly, E. (2014b). Household crowding is associated with higher allostatic load among the Inuit. Journal of Epidemiology and Community Health, 68(4), 363-369.

Ruiz-Castell, M., Muckle, G., Dewailly, E., Jacobson, J. L., Jacobson, S. W., Ayotte, P., \& Riva, M. (2015). Household crowding and food insecurity among Inuit families with school-aged children in the Canadian Arctic. American Journal of Public Health, 105(3), e122-e132.

Shapiro, G. D., Bushnik, T., Sheppard, A. J., Kramer, M. S., Kaufman, J. S., \& Yang, S. (2017). Paternal education and adverse birth outcomes in Canada. Journal of Epidemiology and Community Health, 71(1), 67-72.

Shapiro, G. D., Sheppard, A. J., Bushnik, T., Kramer, M. S., MashfordPringle, A., Kaufman, J. S., \& Yang, S. (2018). Adverse birth outcomes and infant mortality according to registered First Nations status and First Nations community residence across Canada. Canadian Journal of Public Health, 109(5-6), 692-699.

Sheppard, A. J., Shapiro, G. D., Bushnik, T., Wilkins, R., Perry, S., Kaufman, J. S., Kramer, M. S., \& Yang, S. (2017). Birth outcomes among First Nations, Métis and Inuit populations. Health Reports, 28(11), 11-16.

Spurling, G. K., Askew, D. A., Schluter, P. J., Simpson, F., \& Hayman, N. E. (2014). Household number associated with middle ear disease at an urban Indigenous health service: a cross-sectional study. Australian Journal of Primary Health, 20(3), 285-290.

Statistics Canada. (2010). "Aboriginal Peoples Technical Report, 2006 Census, Second Edition. Census year 2006. Catalogue no. 92-569X."

Statistics Canada. (2014). 2006 Census Topic-based tabulations. http:// www12.statcan.gc.ca/census-recensement/2006/dp-pd/tbt/Rp-eng. $\mathrm{cfm} ? \mathrm{LANG}=\mathrm{E} \& \mathrm{APATH}=3 \& \mathrm{DETAIL}=0 \& \mathrm{DIM}=0 \& \mathrm{FL}=$ $\mathrm{A} \& \mathrm{FREE}=0 \& \mathrm{GC}=0 \& \mathrm{GID}=0 \& \mathrm{GK}=0 \& \mathrm{GRP}=0 \& \mathrm{PID}=$ $92766 \& \mathrm{PRID}=0 \& \mathrm{PTYPE}=88971,97154 \& \mathrm{~S}=0 \& \mathrm{SHOWALL}=$ $0 \&$ SUB $=0 \&$ Temporal $=2006 \&$ THEME $=73 \& \mathrm{VID}=0 \& \mathrm{VNAMEE}=$ \&VNAMEF. Accessed 29 Apr 2018.

Statistics Canada. (2017). The housing conditions of Aboriginal people in Canada. Census of Population, 2016. Catalogue no. 98-200X2016021.

Thompson, S., Bonnycastle, M., \& Hill, S. (2020). COVID-19, First Nations and poor housing: "Wash hands frequently" and "selfisolate" akin to "let them eat cake" in First Nations with overcrowded homes lacking piped water. Manitoba: Canadian Centre for Policy Alternatives.

Vogel, J. P., Chawanpaiboon, S., Moller, A. B., Watananirun, K., Bonet, M., \& Lumbiganon, P. (2018). The global epidemiology of preterm birth. Best Practice \& Research. Clinical Obstetrics \& Gynaecology, 52, 3-12.

Publisher's note Springer Nature remains neutral with regard to jurisdictional claims in published maps and institutional affiliations. 